\title{
Deformation of Ordered Mesoporous Silica Structures on Exposure to High Temperatures
}

\author{
John B. Lowe and Richard T. Baker \\ School of Chemistry, University of St Andrews, St Andrews, Fife KY16 9ST, UK \\ Correspondence should be addressed to Richard T. Baker; rtb5@st-andrews.ac.uk
}

Received 14 July 2014; Revised 20 August 2014; Accepted 21 August 2014; Published 15 September 2014

Academic Editor: Anukorn Phuruangrat

Copyright ( 2014 J. B. Lowe and R. T. Baker. This is an open access article distributed under the Creative Commons Attribution License, which permits unrestricted use, distribution, and reproduction in any medium, provided the original work is properly cited.

\begin{abstract}
Ordered mesoporous silica materials are of interest for a wide range of applications. In many of these, elevated temperatures are used either in the preparation of the material or during its use. Therefore, an understanding of the effect of high temperature treatments on these materials is desirable. In this work, a detailed structural study is performed on silicas with three representative pore structures: a 2-D hexagonal pore arrangement (SBA-15), a continuous 3D cubic bimodal pore structure (KIT-6), and a 3D large cage pore structure (FDU-12). Each silica is studied as prepared and after treatment at a series of temperatures between 300 and $900^{\circ} \mathrm{C}$. Pore structures are imaged using Transmission Electron Microscopy. This technique is used in conjunction with Small-Angle X-ray Diffraction, gas physisorption, and ${ }^{29} \mathrm{Si}$ solid state Nuclear Magnetic Resonance. Using these techniques, the pore size distributions, the unit cell dimensions of the mesoporous structures, and the relative occupancy of the distinct chemical environments of Si within them are cross correlated for the three silicas and their evolution with treatment temperature is elucidated. The physical and chemical properties before, during, and after collapse of these structures at high temperatures are described as are the differences in behavior between the three silica structures.
\end{abstract}

\section{Introduction}

Mesoporous solids, especially those with an ordered pore structure, possess unusual and interesting properties including very high specific surface areas, chemical and thermal stability in many environments, interconnected pore structures, and uniform pore size and shape which, furthermore, can be predetermined to a large extent by modification of the preparation parameters. As a consequence, this group of materials is in demand for a wide range of current and potential applications. The most widely studied group of ordered mesoporous materials are those consisting of amorphous silica but with ordered pore structures. These are typically prepared by the self-assembly of surfactantbased micelles in the presence of a silicon source such as tetraethoxysilane and subsequent removal of the organics to leave the mesoporous silica. Although these products are not crystalline in the conventional sense, the periodicallyrepeating pore structures can be assigned unit cells and space groups. An extensive family of these Ordered Mesoporous
Silicas (OMSs) has been reported and features a wide range of pore structure symmetries including hexagonal $p 6 \mathrm{~mm}$ (MCM-41 [1], SBA-15 [2], SBA-3 [3]), cubic Ia3d (MCM-48 [4], KIT-6 [5], FDU-5 [6]), cubic Im3m (SBA-16 [7]), and cubic Fm-3m (FDU-12 [8]). The pore structures of the three representative materials chosen for the current study, SBA15, KIT-6, and FDU-12, are presented in Figure 1 [9]. OMS materials are under consideration for many fields of application such as heterogeneous catalysis [10-13], gas adsorption [14] (including hydrogen storage [15]), drug delivery [16, 17], and molecular separation [4]. Depending on the application, the OMS may require further chemical modification. The pore surfaces may be functionalised by postsynthesis grafting $[14,17,18]$ or by addition of the desired functional groups during the initial self-assembly process [17]. Furthermore, a second solid phase may be impregnated into the pores, for example, to provide active catalytic sites [19]. In a very fruitful development, this process can be taken one step further. The OMS can be used as a mould into which the precursor of a different solid phase is introduced, often by 


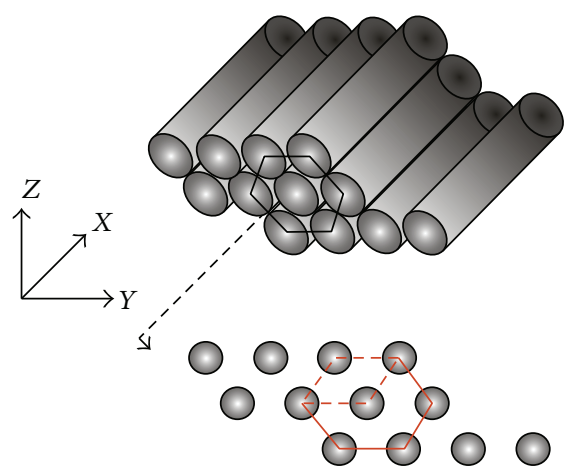

(a)

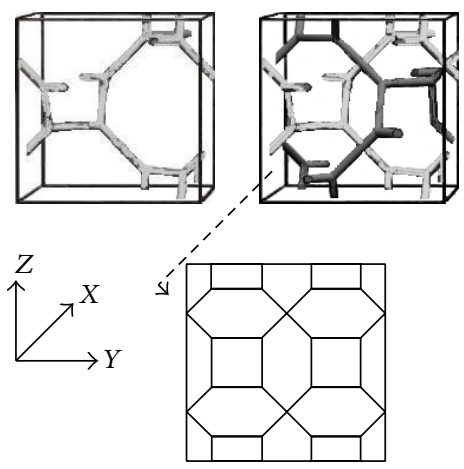

(b)

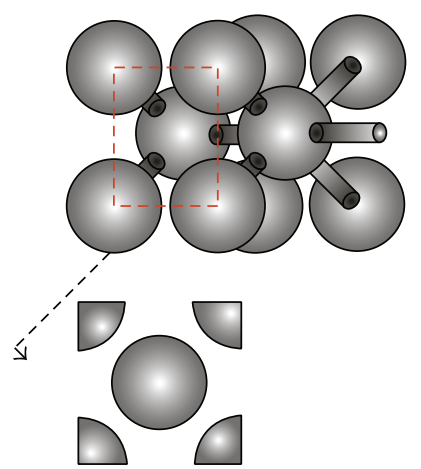

(c)

FIgURE 1: Pictorial representation of (a) SBA-15, (b) KIT-6, and (c) FDU-12. Only the pore structures are shown; the surrounding pore walls are removed for clarity. The pore size and spacings are not to scale. Front elevation highlights the (100) lattice direction and unit cell.

impregnation of a solution. The second phase is then formed within the pore structure of the OMS, usually by calcination, and finally the original OMS is removed by dissolution to leave an inverse ordered mesoporous structure comprised of the second material. This process is known as hard templating or nanocasting [20-22].

This group of techniques has been used to create a series of novel ordered mesoporous materials, often crystalline, including metal oxides [23, 24], metal sulphides [25], and polymers [26] which exhibit the novel properties-such as high specific surface area-seen in the parent OMS. Fundamental to this methodology is the OMS itself, which must possess sufficient chemical and thermal stability to survive the first steps of the nanocasting process without losing its pore structure. For some preparations, these factors may make hard templating difficult. For example, the preparation of mesoporous semiconductor materials is problematic because of their high crystal growth temperature [27].

In the synthetic methods involved in nanocasting, in surface modification and in second phase impregnation the OMS is exposed to elevated temperatures. This is also true during applications of OMS materials as, for example, heterogeneous catalysts and gas storage materials. For these reasons, and with a view to these applications, it is important to understand better the thermal stability and thermal evolution of OMS materials. In a detailed thermogravimetric and in situ high temperature XRD (HTXRD) study of a number of OMS materials including SBA-15, Kleitz et al. concentrated on the decomposition of organic templates during the initial calcination and the related changes in pore structure [28]. In a gas adsorption study, Ryoo and coworkers reported a decrease in mesopore diameter with increasing treatment temperature in SBA-15 and identified the existence of micropores interconnecting the mesopores [29]. Shah and Ramaswamy also used HTXRD on SBA-15 and reported thermal contraction with increasing temperature but pore stability up to $1200^{\circ} \mathrm{C}$ [30]. Huang et al. saw pore shrinkage in ultra large pore FDU-12, when they applied calcination temperatures up to $450^{\circ} \mathrm{C}$ [31] and Kruk and Hui were able to modify FDU-12 so that its spherical pores became isolated, or entombed, after calcinations at $450-640^{\circ} \mathrm{C}$ [32].
The latter effect is of interest for the formation of low dielectric insulators and a similar effect-in this case forming entombed cylindrical pores-was reported by Mandal and Kruk for SBA-15 [33].

Here, three widely used and representative OMS materials with different pore structures, SBA-15, KIT-6, and FDU12 , were studied as prepared and after thermal treatment at a wide range of temperatures. Transmission Electron Microscopy (TEM), (ex situ) Small-Angle X-ray diffraction (SAXS), gas physisorption, and ${ }^{29}$ Si Magic Angle Spinning Nuclear Magnetic Resonance (MAS-NMR) were used in each case to obtain the pore size distributions, the unit cell dimensions of the mesopore structures, and the relative occupancy of the distinct chemical environments of Si within them. These data were cross correlated and the evolution of the three OMS structures with treatment temperature was elucidated, resulting in a comprehensive and systematic comparative study.

\section{Experimental}

SBA-15 silicas were synthesised according to a published method using the triblock copolymer surfactant, Pluronic $\mathrm{P} 123\left(\mathrm{EO}_{20} \mathrm{PO}_{70} \mathrm{EO}_{20}\right)$, where $\mathrm{EO}$ is poly(ethylene oxide) and PO is poly(propylene oxide) [2]. In a typical synthesis, $2 \mathrm{~g}$ of Pluronic P123 was added to $15 \mathrm{~cm}^{3}$ of distilled water and $60 \mathrm{~cm}^{3}$ of $2 \mathrm{M} \mathrm{HCl}$ and stirred at $40^{\circ} \mathrm{C}$ for 8 hours. $4.25 \mathrm{~g}$ tetraethyl orthosilicate (TEOS) was added and the mixture was stirred for 24 hours at the same temperature.

KIT-6 silicas were synthesised according to a published method using the triblock copolymer surfactant, Pluronic P123 $\left(\mathrm{EO}_{20} \mathrm{PO}_{70} \mathrm{EO}_{20}\right)$ [5]. In a typical synthesis, $6 \mathrm{~g}$ of Pluronic P123 was added to $180 \mathrm{~cm}^{3}$ of distilled water and $50 \mathrm{~cm}^{3}$ of $2 \mathrm{M} \mathrm{HCl}$ and stirred at $35^{\circ} \mathrm{C}$ for 6 hours. $6 \mathrm{~g}$ of $n$ butanol was added and the mixture was stirred for a further hour at $35^{\circ} \mathrm{C} .12 .48 \mathrm{~g}$ TEOS was added and this mixture was stirred for 24 hours at the same temperature.

FDU-12 silicas were synthesised according to a published method using the triblock copolymer surfactant, Pluronic F127 $\left(\mathrm{EO}_{106} \mathrm{PO}_{70} \mathrm{EO}_{106}\right)$ [8]. In a typical synthesis, $2 \mathrm{~g}$ of Pluronic F127 and $5 \mathrm{~g}$ of potassium chloride were added to 
$120 \mathrm{~cm}^{3}$ of $2 \mathrm{M} \mathrm{HCl}$ and the resulting mixture was stirred at $40^{\circ} \mathrm{C}$ until clear. $2 \mathrm{~g}$ of trimethylbenzene was added dropwise and the mixture was stirred for 24 hours at $40^{\circ} \mathrm{C} .8 .3 \mathrm{~g}$ TEOS was added and the mixture was stirred for a further 24 hours at the same temperature.

For all three silica syntheses, the mixtures prepared as above were transferred to a PTFE container and placed in a muffle furnace for hydrothermal treatment at $100^{\circ} \mathrm{C}$ for $24 \mathrm{~h}$. The resulting solid materials were washed and filtered three times using distilled water and dried at $50^{\circ} \mathrm{C}$ overnight before being calcined at $500^{\circ} \mathrm{C}$ for $5 \mathrm{~h}$ (with a ramp rate of $1^{\circ} \mathrm{C} \mathrm{min}{ }^{-1}$ ) in a tube furnace (Carbolite STF) to remove the surfactants and any remaining organic compounds. All reagents were purchased from Sigma-Aldrich.

Each of the three OMS products was subdivided into equal measures of approximately $200 \mathrm{mg}$ for subsequent thermal treatment. This quantity generally was sufficient to allow for the full series of analytical techniques to be applied since these were nondestructive and caused only minimal loss of sample. The thermal treatment consisted of heating the material in air to the desired temperature at a ramp rate of $1^{\circ} \mathrm{C} \mathrm{min}^{-1}$ and applying a dwell of $5 \mathrm{~h}$. Treatment temperatures, $\mathrm{T}$, of 300, 400, 450, 500, 550, 600, $650,700,800$, and $900^{\circ} \mathrm{C}$ were applied. This temperature range was chosen to include all temperatures of relevance to the various applications of OMS materials, including catalysis and nanocasting. Samples are named as follows. The prefix indicates the OMS structure type and the suffix indicates the treatment temperature. In addition, the untreated, asprepared samples will be denoted by the suffix, AP. As an example, SBA- 15 treated at $900^{\circ} \mathrm{C}$ is referred to as S- 900 .

Nitrogen adsorption isotherms were measured at $-196^{\circ} \mathrm{C}$ using a Micromeritics ASAP 2020 volumetric adsorption analyser. All samples were pretreated before analysis by outgassing overnight at $120^{\circ} \mathrm{C}$ under vacuum.

SAXS patterns were recorded using a PANalytical Empyrean Diffractometer in reflectance geometry using $\mathrm{Cu}$ $\mathrm{K} \alpha_{1}$ radiation (wavelength $\lambda=0.1540598 \mathrm{~nm}$ ). The incident beam was collimated by a series of slits and a beam mask. Diffraction data were recorded in the range $2 \theta=0.5-5^{\circ}$ with a step size of $0.01^{\circ}$. The powder samples were pressed into the $0.5 \mathrm{~mm}$ deep, $16 \mathrm{~mm}$ diameter well in a standard circular steel reflectance holder with a PTFE liner.

TEM images were obtained using a JEOL JEM 2011 instrument operating with $\mathrm{LaB}_{6}$ filament and at an accelerating voltage of $200 \mathrm{kV}$. The images were captured and analysed using Digital Micrograph 3.4.4 software operating a Gatan CCD camera.

Solid-state ${ }^{29} \mathrm{Si}$ MAS-NMR spectra were obtained at $79.44 \mathrm{MHz}$ at a spin rate of $6.8 \mathrm{KHz}$ on a Varian VNMRS 400 spectrometer for all SBA- 15 and KIT- 6 samples. The spectra for the FDU-12 samples F-AP, F-450, and F-600 were obtained at $59.63 \mathrm{MHz}$ and at a spin rate of $6.0 \mathrm{KHz}$ on a Varian Unity Inova 300 spectrometer with $60 \mathrm{~s}$ delay between scans. The amount of sample available for NMR was small because of the need to use a single batch of material for all treatment temperatures. Because of the particularly small amount of sample available, the spectrum for F- 900 was run at $79.5 \mathrm{MHz}$ on a Bruker Avance III spectrometer with 180 s delay between scans using a $9.4 \mathrm{~T}$ wide bore superconducting magnet.

For each of the OMS materials, values for interplanar spacings, $\mathbf{d}$, obtained from the SAXS patterns were used to calculate the corresponding unit cell parameters $\left(\mathbf{a}_{0}\right)$.

\section{Results}

3.1. Gas Physisorption. In order to determine the structural changes for the three OMS materials of interest, a series of nitrogen physisorption isotherms were produced from each thermally treated sample and the as-prepared samples (AP). Isotherm plots for the three AP samples together and for the individual samples as a function of treatment temperature are presented in Figure 2. Both SBA-15 and KIT-6 give rise to physisorption isotherms of Type IV with Type $\mathrm{H} 3$ hysteresis. This behaviour is typical of mesoporous materials within whose pores capillary condensation occurs. The FDU-12 material also gave an isotherm of Type IV but showed Type $\mathrm{H} 2$ hysteresis. This is typical of mesoporous materials with bottleneck-shaped pores. The isotherms were therefore as expected for all three OMS materials. The main effect of increasing pretreatment temperature was to decrease the extent of adsorption and desorption and so to reduce the size of the hysteresis loop. This shows a dramatic collapse for FDU-12 which is discussed in more detail below. To quantify these changes and so compare them more closely, it is best to obtain surface area and pore size data from these isotherms. Using Brunauer-Emmett-Teller (BET), the specific surface area (SSA, $\mathrm{m}^{2} \mathrm{~g}^{-1}$ ) was obtained. The Barrett-Joiner-Halenda (BJH) algorithm was utilised to obtain pore size distribution (PSD) and specific mesopore volume $\left(V_{\text {meso }}, \mathrm{cm}^{3} \mathrm{~g}^{-1}\right.$, pore diameters of 2 to $50 \mathrm{~nm}$ ) and the $t$-plot method was used to obtain values of specific micropore volume $\left(V_{\text {micro }}, \mathrm{cm}^{3} \mathrm{~g}^{-1}\right.$, pore diameters under $2 \mathrm{~nm}$ ). Figure 3 presents plots of $V_{\text {meso }}$, $V_{\text {micro }}$, and SSA against treatment temperature for the three OMS materials. For all three materials, $V_{\text {meso }}$ is much larger than $V_{\text {micro }}$. On increasing treatment temperature for SBA15 and KIT-6, SSA first decreased noticeably for $\mathrm{T}=400^{\circ} \mathrm{C}$ and continued to decrease roughly linearly until reaching a point of inflection at $\mathbf{T} \sim 550^{\circ} \mathrm{C}$, after which it declined more sharply. Nevertheless, for $\mathrm{T}=900^{\circ} \mathrm{C}$, significant SSA remained for both SBA-15 $\left(160 \mathrm{~m}^{2} \mathrm{~g}^{-1}, 20 \%\right.$ of the initial value) and KIT-6 (260 $\mathrm{m}^{2} \mathrm{~g}^{-1}$ and $\left.34 \%\right)$. The SSA appeared to be approaching a plateau for SBA-15 at this temperature but this was not the case for KIT- 6 . These same trends are closely paralleled in the plots of $V_{\text {meso }}$ against $\mathbf{T}$. The corresponding fall in $V_{\text {meso }}$ suggests that the internal pore structure was in the process of contracting. Despite this trend, both materials still exhibited significant mesoporosity-around 41 and $44 \%$ of the initial values for SBA-15 and KIT-6, respectively-for $\mathrm{T}=900^{\circ} \mathrm{C}$. In Figure 3(c), the corresponding plots for FDU12 showed only small decreases in SSA and $V_{\text {meso }}$ indicating a high tolerance to high temperature treatments up to and including $\mathrm{T}=500^{\circ} \mathrm{C}$ after which both parameters suffered a rapid decline from $\mathrm{T}=700^{\circ} \mathrm{C}$, both reaching values close to zero at higher temperatures. This behavior indicates that differences in pore structure had a considerable influence on 

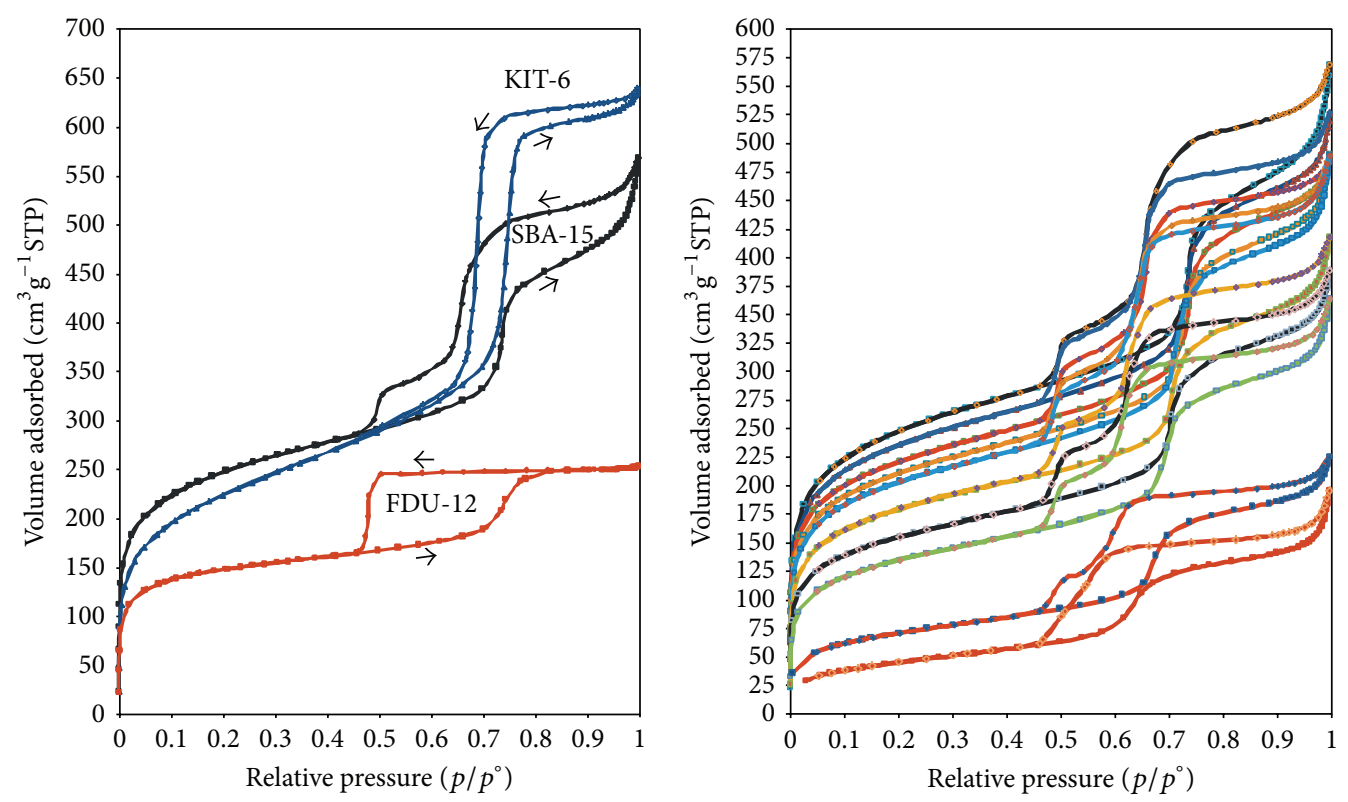

(a)

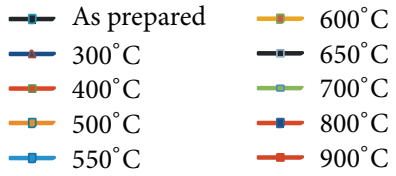

(b)
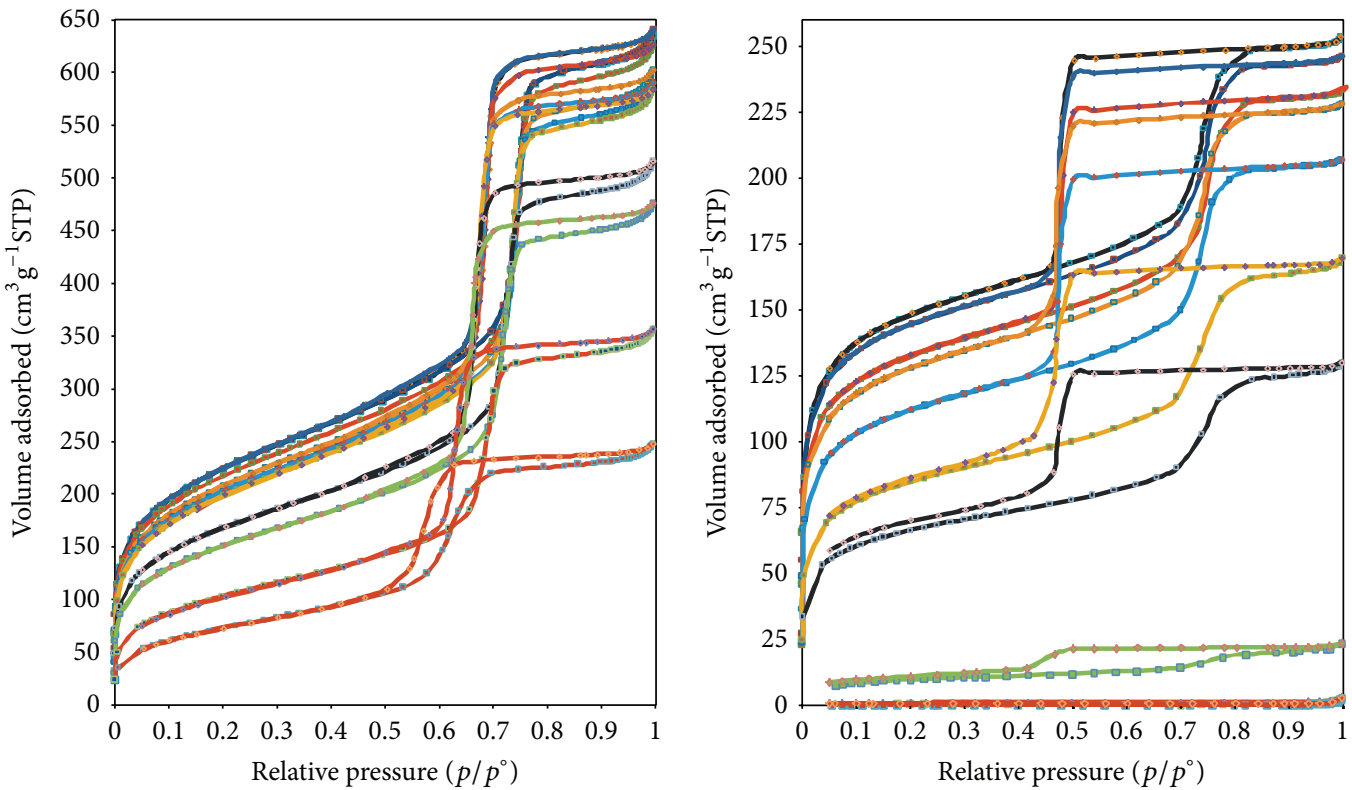

$$
\begin{array}{ll}
\rightarrow \text { As prepared } & \rightarrow 600^{\circ} \mathrm{C} \\
\rightarrow-300^{\circ} \mathrm{C} & -650^{\circ} \mathrm{C} \\
\rightarrow-400^{\circ} \mathrm{C} & -700^{\circ} \mathrm{C} \\
\rightarrow-500^{\circ} \mathrm{C} & --800^{\circ} \mathrm{C} \\
\rightarrow-550^{\circ} \mathrm{C} & --900^{\circ} \mathrm{C}
\end{array}
$$

(c)

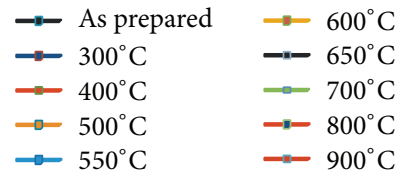

(d)

FIGURE 2: (a) Nitrogen physisorption isotherms for all three OMS materials in their as-prepared (AP) states. Arrows indicate the adsorption and desorption branches. Sorption isotherms for all pretreatment temperatures and AP sample as indicated for (b) SBA-15, (c) KIT-6, and (d) FDU-12. 


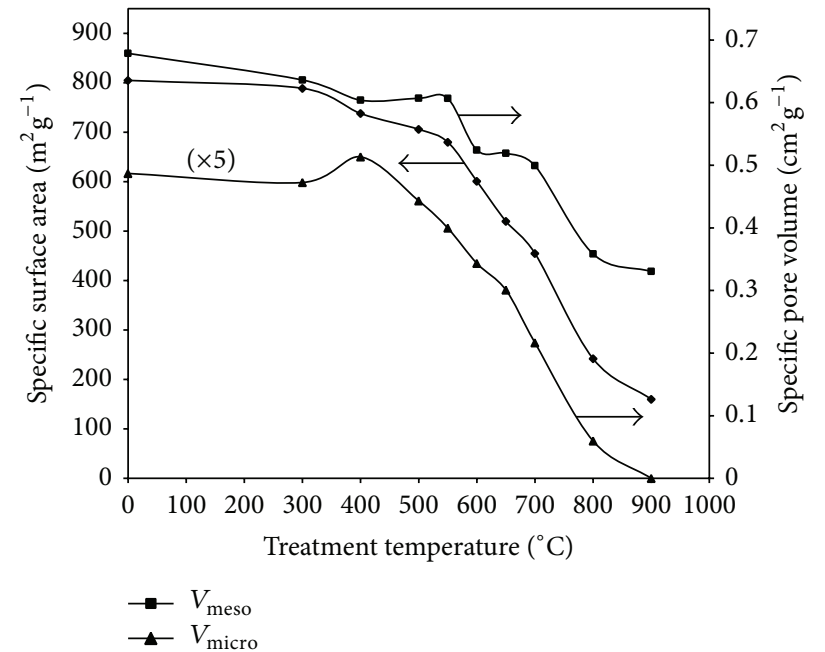

(a)

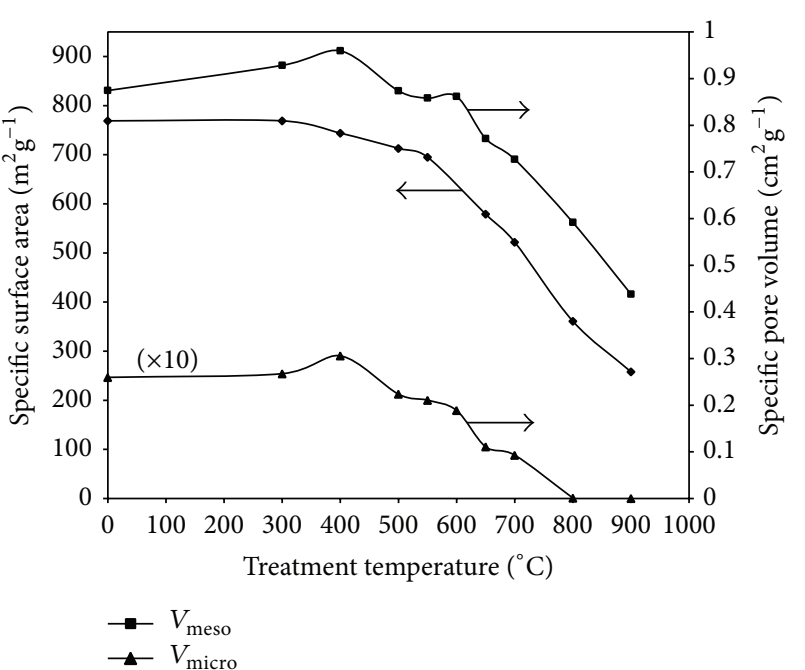

(b)

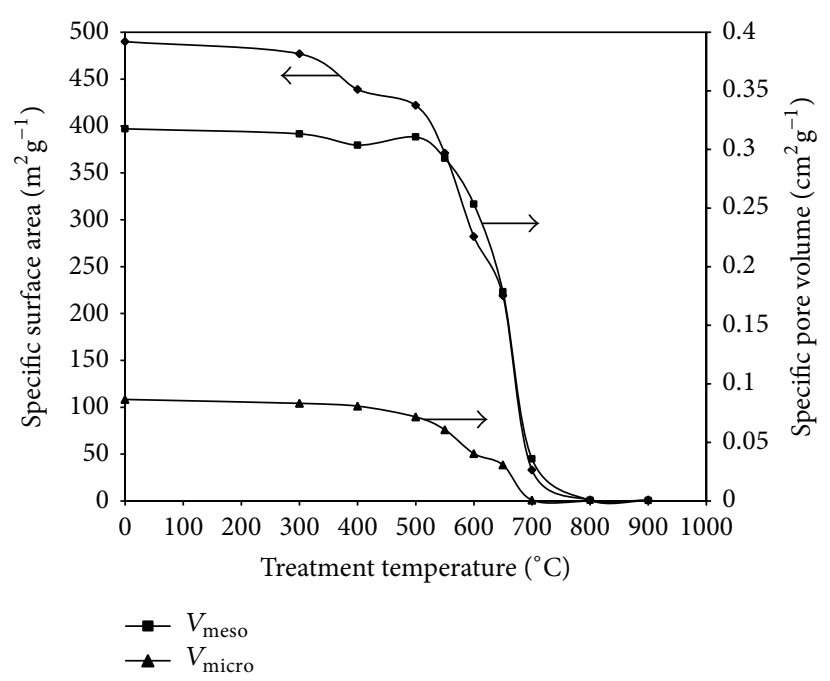

(c)

Figure 3: Plots of specific surface area $\left(\mathrm{m}^{2} \mathrm{~g}^{-1}\right)$ and specific micro $\left(V_{\text {micro }}\right)$ and mesopore $\left(V_{\text {meso }}\right)$ volume $\left(\mathrm{cm}^{3} \mathrm{~g}^{-1}\right)$ as functions of pretreatment temperature for (a) SBA-15, (b) KIT-6, and (c) FDU-12. Data points at $0^{\circ} \mathrm{C}$ are for as-prepared (AP) materials. $V_{\text {micro }}$ values have been multiplied by a factor of 5 for SBA-15 and of 10 for KIT- 6 for clarity.

the structural integrity of these OMS materials under high temperature treatments.

This phenomenon is strikingly verified by reviewing the plots of pore size distribution in the mesopore region presented in Figure 4. For all three as-prepared materials, a clear, single peak was observed and peak size decreased as treatment temperature increased. This corresponds to the significant loss of porosity observed for all samples in Figure 3. For SBA-15 and KIT-6, there is a smooth trend in which the peak maximum shifted to lower pore width values as $\mathbf{T}$ increased. The pore widths for all three AP and 900 samples are given in Table 1.

These shifts in pore peak position also became more marked with increasing $\mathbf{T}$ which appears to be an approximately exponential (Arrhenius-type) relationship. This is consistent with the thermally-activated shrinkage of the pores in these two materials. The behavior of FDU-12 was very different, however. Figure 4(c) indicates that no significant change in pore width occurred, although, as in the other two materials, the peak height did fall with increasing $\mathbf{T}$, in this case, in fact, to zero.

These gas adsorption results strongly indicate that loss of porosity and surface area occurred in SBA-15 and KIT- 6 by gradual shrinkage in pore size while in FDU-12 it occurred by rapid loss of individual pores.

Returning to Figure 3, it is interesting to review the trends in $V_{\text {micro }}$. In general, $V_{\text {micro }}$ increases in the following order: KIT-6 < FDU-12 < SBA-15. This is consistent with the pore structures of these materials. SBA-15 is known to have microchannels between mesopores [34]; FDU-12 has cylindrical micropore channels between spherical mesopores but KIT-6 appears to have fewer microchannels between its 


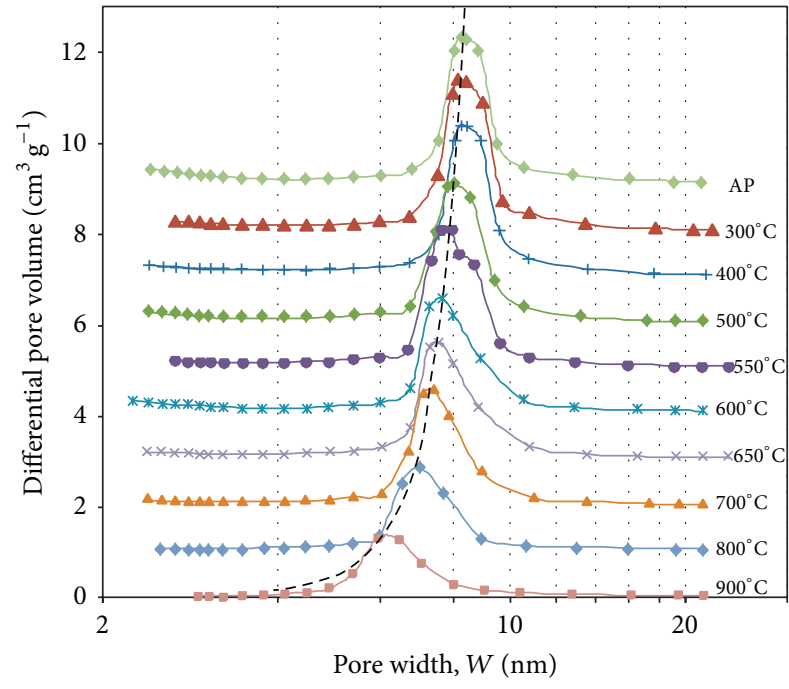

(a)

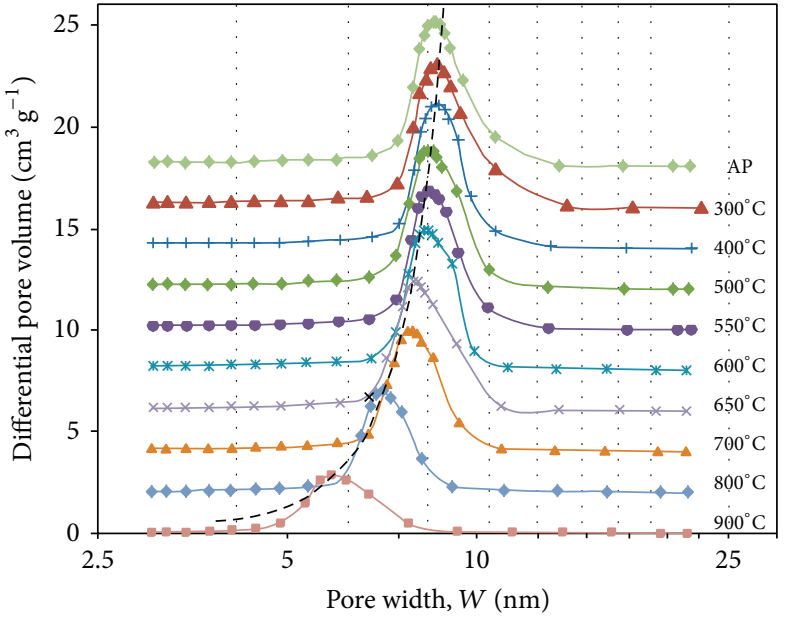

(b)

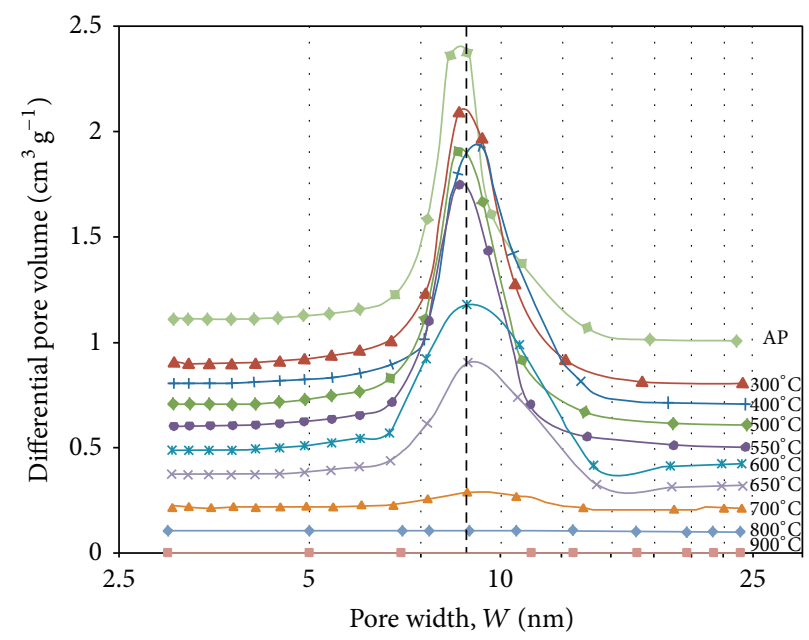

(c)

FIGURE 4: Pore size distributions for (a) SBA-15, (b) KIT-6, and (c) FDU-12 obtained from BJH adsorption isotherms. Plots have been offset incrementally in the $y$-axis by (a) 1.0 , (b) 2.0 , and (c) $0.1 \mathrm{~cm}^{3} \mathrm{~g}^{-1}$ for clarity.

TABLE 1: Values for unit cell parameters $\left(\mathbf{a}_{\mathbf{0}} \mathbf{1}-\mathbf{a}_{\mathbf{0}} \mathbf{3}\right)$, interplanar spacings $(\mathbf{d})$, pore width $(\mathbf{w})$, and pore wall thickness $(\mathbf{t})$ obtained using the method indicated (BJH, SAXS, and TEM) for the samples indicated. All values are in $\mathrm{nm}$. Values of $\mathbf{a}_{0}$ are calculated from the corresponding $\mathbf{d}_{\text {SAXs }}$ value. Miller indices are given in italics below each value of $\mathbf{d}$.

\begin{tabular}{|c|c|c|c|c|c|c|c|c|c|c|}
\hline Sample & $\mathbf{w}_{\mathrm{BJH}}$ & $\mathbf{d}_{\mathrm{SAXS}} 1$ & $d_{\mathrm{SAXs}} 2$ & $\mathrm{~d}_{\mathrm{SAXs}} 3$ & $a_{0} 1$ & $a_{0} 2$ & $a_{0} 3$ & $\mathbf{d}_{\mathrm{TEM}}$ & $\mathbf{w}_{\text {TEM }}$ & $\mathbf{t}_{\mathrm{TEM}}$ \\
\hline S-AP & 8.4 & $\begin{array}{c}9.8 \\
(100)\end{array}$ & $\begin{array}{c}5.9 \\
(210)\end{array}$ & $\begin{array}{c}5.1 \\
(100)^{\mathrm{a}}\end{array}$ & 11.3 & 11.7 & 11.8 & $\begin{array}{c}9.5 \\
(100)\end{array}$ & 7.5 & 2.2 \\
\hline S-900 & 6.2 & $\begin{array}{c}7.8 \\
(100)\end{array}$ & $\begin{array}{c}4.1 \\
(210) \\
\end{array}$ & $\begin{array}{c}3.1 \\
(100)^{\mathrm{a}}\end{array}$ & 8.8 & 8.2 & 7.0 & $\begin{array}{c}8.5 \\
(100) \\
\end{array}$ & 5.5 & 2.2 \\
\hline K-AP & 8.6 & $\begin{array}{c}8.9 \\
(211)\end{array}$ & $\begin{array}{c}5.4 \\
(400)\end{array}$ & $\begin{array}{c}4.7 \\
(332)\end{array}$ & 21.8 & 21.5 & 22.0 & $\begin{array}{c}8.3 \\
(211)\end{array}$ & 7.0 & 2.8 \\
\hline K-900 & 5.9 & $\begin{array}{c}7.2 \\
(211) \\
\end{array}$ & $\begin{array}{c}4.4 \\
(400) \\
\end{array}$ & $\begin{array}{c}3.8 \\
(332) \\
\end{array}$ & 17.7 & 17.7 & 18.1 & $\begin{array}{c}7.3 \\
(211) \\
\end{array}$ & 5.5 & 4.5 \\
\hline F-AP & 8.6 & $\begin{array}{l}11.7 \\
(111)\end{array}$ & $\begin{array}{c}6.7 \\
(220)\end{array}$ & - & 20.3 & 18.8 & - & $\begin{array}{l}12.1 \\
(111)\end{array}$ & 9.4 & 4.7 \\
\hline F-900 & - & $\begin{array}{l}10.6 \\
(111)\end{array}$ & $\begin{array}{c}6.5 \\
(220)\end{array}$ & - & 18.4 & 18.3 & - & - & - & - \\
\hline
\end{tabular}

\footnotetext{
${ }^{a}$ Second order diffraction.
} 


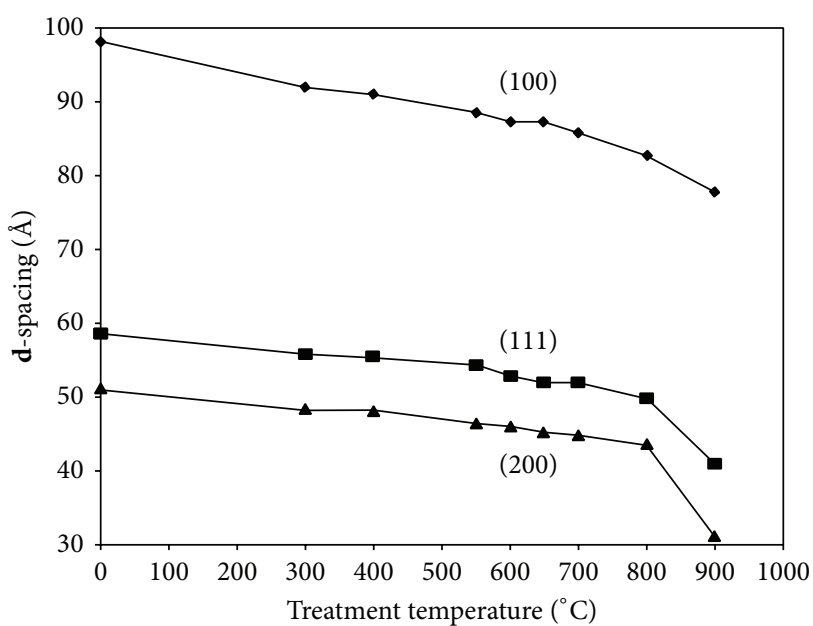

(a)

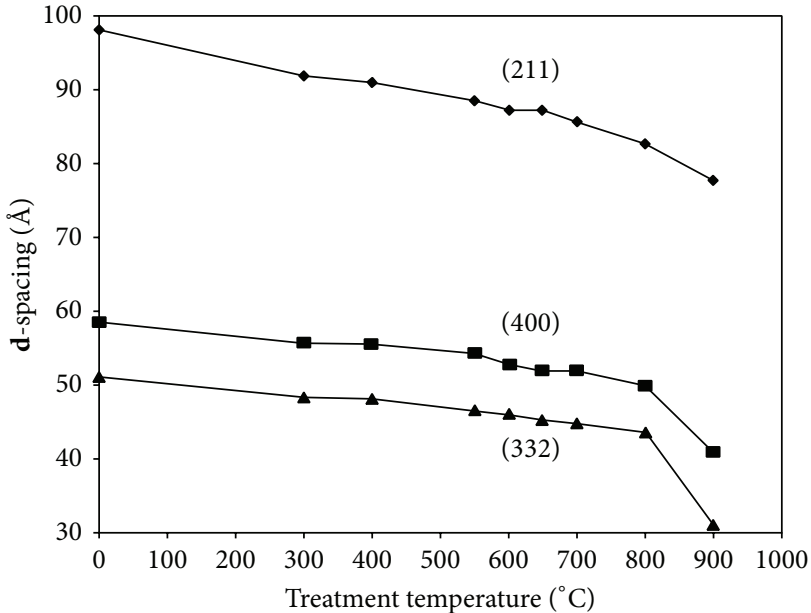

(b)

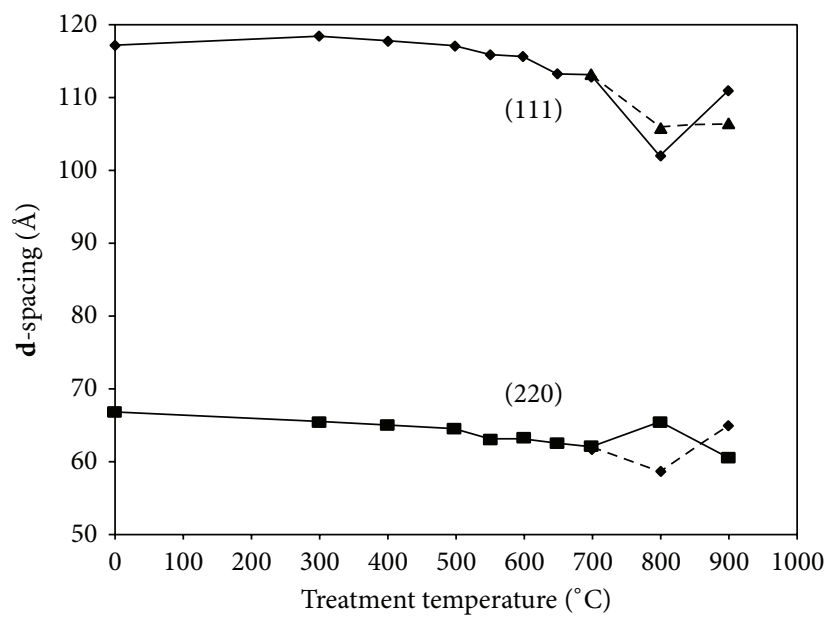

(c)

FIGURE 5: Derived d-spacing data from SAXS analysis (a) SBA-15, (b) KIT-6, and (c) FDU-12. The dashed line in (c) represents repeat data of samples F-800 and F-900.

wormhole-like mesopores [34]. In all cases, $V_{\text {micro }}$ decreases with increasing $\mathbf{T}$ in a similar way to $V_{\text {meso }}$. For FDU-12, both parameters fall to zero at $700-800^{\circ} \mathrm{C}$. In SBA-15 and KIT-6, however, $V_{\text {micro }}$ falls to zero while $V_{\text {meso }}$ remains at relatively high values, even at $\mathrm{T}=900^{\circ} \mathrm{C}$.

3.2. Small Angle X-Ray Scattering. SAXS patterns were recorded for all three OMS materials after all treatments. These are included in Supplementary Information as Figures S1-S4 (see Supplementary Material available online at http:// dx.doi.org/10.1155/2014/754076). The positions of peaks in these patterns were used to extract values of interplanar spacings, $\mathbf{d}$, to which Miller indices-relating to the ordered pore structures-were assigned. Interplanar spacings and unit cell dimensions derived from them are given in Table 1 for the AP and 900 samples. The evolution of these interplanar spacings with treatment conditions is presented in Figure 5 for each OMS type.
Within each of the three plots, the trends in all d-spacing values showed a high degree of similarity, indicating that the data were self-consistent. A general trend of decreasing d-spacing with increasing treatment temperature was seen for all three OMS materials. This implies shrinkage of the unit cells with increasing $\mathbf{T}$ in each case. The shrinkage of the unit cells of SBA-15 and KIT- 6 was more marked than that of FDU-12. For example, the largest d-spacing for FDU$12\left(\mathbf{d}_{111}\right)$ showed a relative decrease to $\mathbf{T}=700^{\circ} \mathrm{C}$ of $2-3$ times more than the largest spacing for the SBA-15 (the $\mathbf{d}_{100}$ ) and the KIT-6 $\left(\mathbf{d}_{211}\right)$. The gas adsorption results, presented in Figures 3 and 4, indicated that FDU-12 showed complete loss of SSA and open pore structure after treatment at the highest temperatures. For this reason, the SAXS patterns for the samples F-800 and F-900 were obtained twice. The corresponding $\mathbf{d}$-spacings showed large variances which can be attributed to the small amounts of ordered material remaining in these samples which in turn gave rise to small 


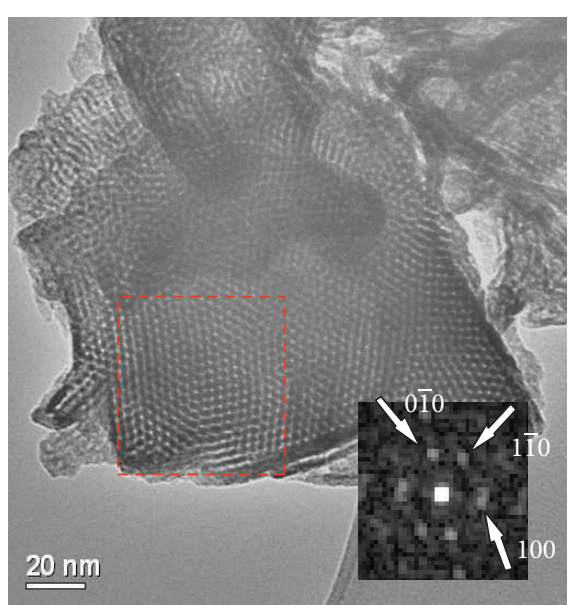

(a)

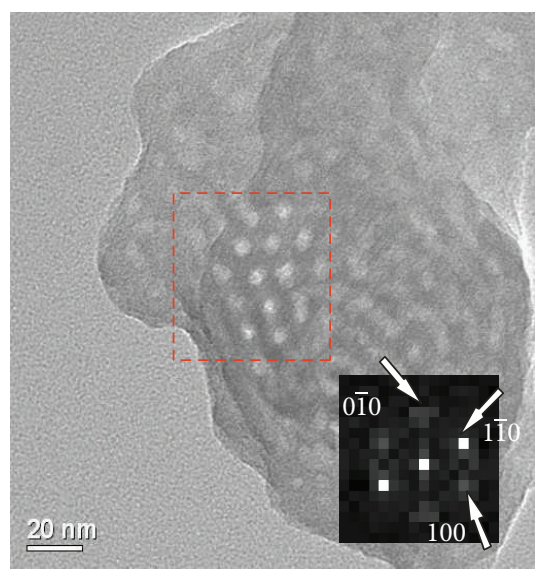

(c)

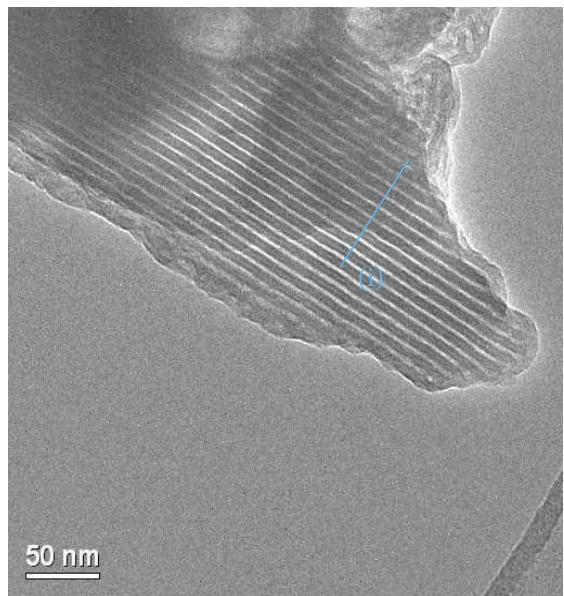

(b)

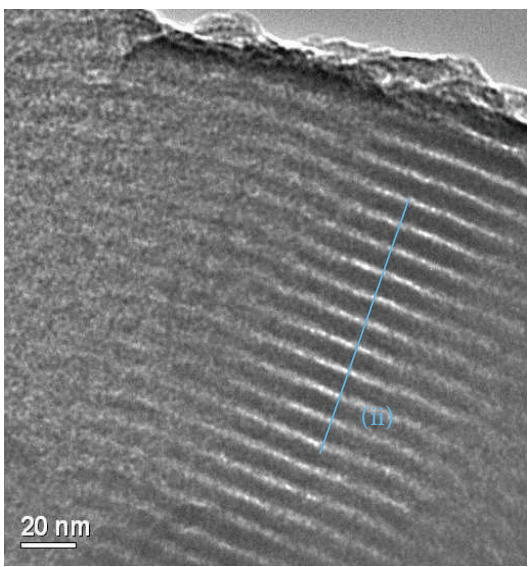

(d)

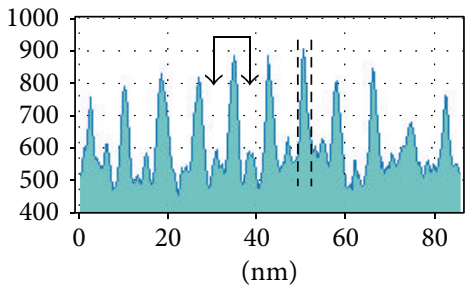

(i)

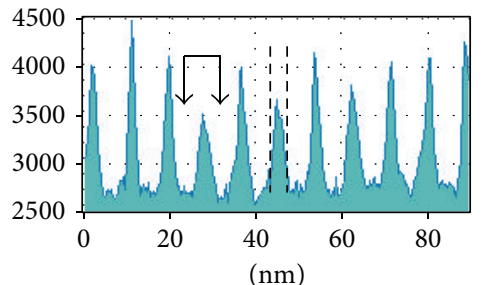

(ii)

FIGURE 6: TEM images for SBA-15. (a) Image of the pore structure in S-AP. The DDP obtained from the area indicated by the dashed box is inset and Miller indices are given. (b) Image showing the linear pore structure of S-AP. The variation of contrast along the line in the image is given in (i) where pore spacing (arrows) and wall thickness (dashed lines) are indicated. (c) Image of S-900. The DDP obtained from the area indicated by the dashed box is inset and Miller indices are given. (d) Image showing the linear pore structure of S-900. The variation of contrast along the line in the image is given in (ii) where pore spacing (arrows) and wall thickness (dashed lines) are indicated. (e) Image of S-900 showing a region of essentially nonporous amorphous silica.

SAXS peaks. The fact that $\mathbf{d}$-spacings were resolved at all in these two samples, however, is noteworthy, given the hypothesis of pore structure collapse.

\subsection{Transmission Electron Microscopy. Figures 6-8 present} the TEM analyses of the three OMS materials, each in both their as-prepared state and after treatment at $900^{\circ} \mathrm{C}$. Two methods were employed to obtain information on the pore structures. Firstly, Digital Diffraction Patterns (DDPs) were obtained by applying the Fourier transform to selected areas of the TEM images. The d-spacings were then calculated from these. Secondly, line scans giving the variation in contrast as a function of position were generated from selected images. These were used to extract pore and wall widths. These data are given in Table 1.
Figures 6(a) and 6(b) show the long-range ordering in the as-prepared SBA-15 material viewed in the $x$ - and $y$ directions (see Figure 1(a)), respectively. After heating at $900^{\circ} \mathrm{C}$, some structured regions were still observed, as in Figures 6(c) and 6(d), but essentially nonporous material such as that seen in Figure 6(e) was now also seen. This distinct partitioning of ordered and nonordered areas was evident throughout the TEM study of this sample. Interplanar spacings were obtained from the DDPs and values for the pore and wall thicknesses in these structures were measured from plots such as those given in parts (i) and (ii) of the figure. These are presented in Table 1 and show good agreement with the corresponding data obtained from SAXS. Ongoing from the S-AP to the S-900 sample, both the unit cells of the pore structure and the pores themselves appeared to have decreased in size while no change in wall thickness was observable in TEM. 


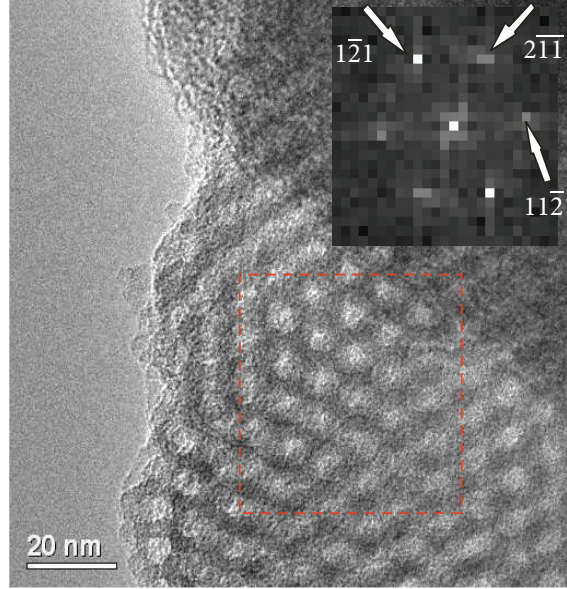

(a)

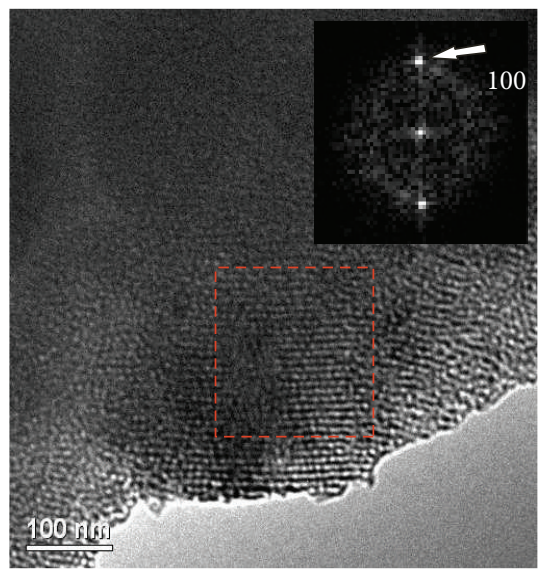

(c)

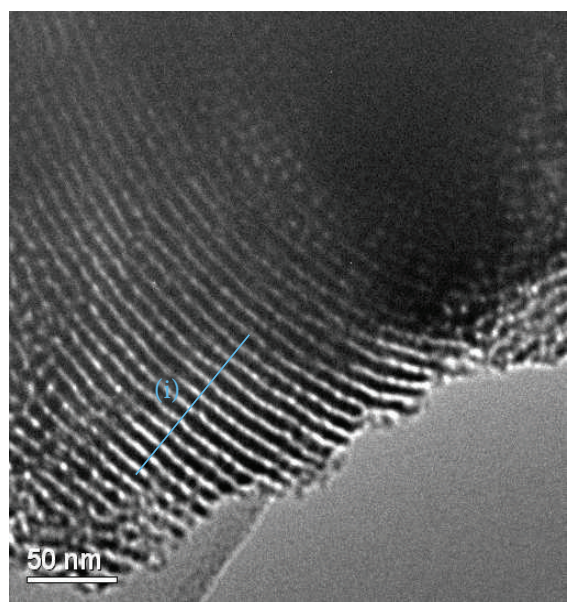

(b)

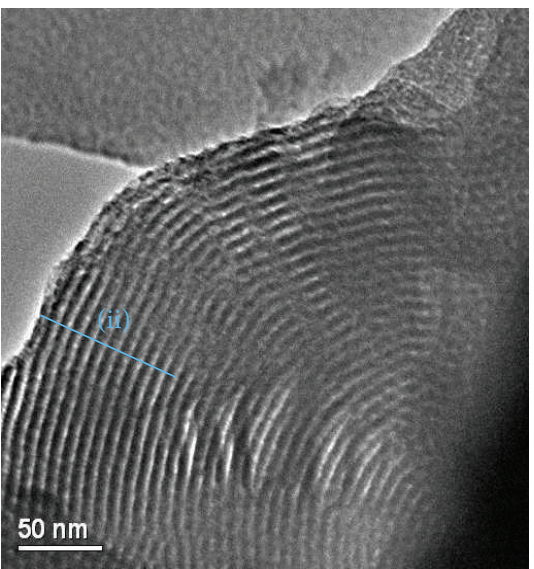

(d)

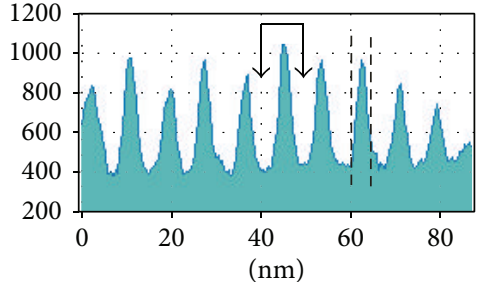

(i)

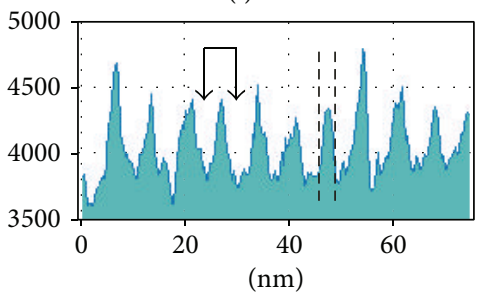

(ii)

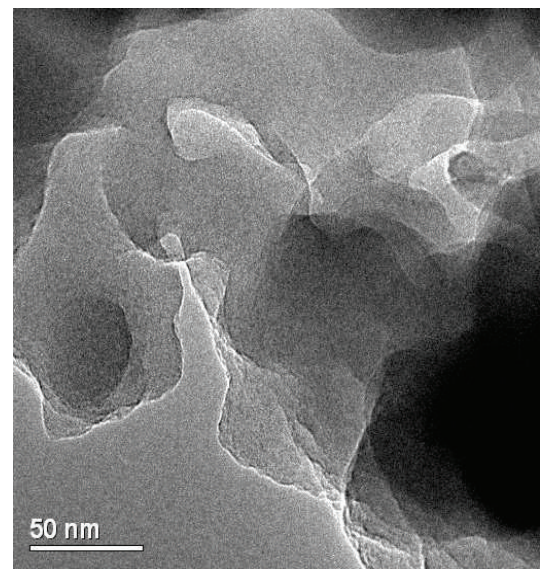

(e)

FIGURE 7: TEM images for KIT-6. (a) Image of the pore structure in K-AP with DDP inset obtained from the area indicated by the dashed box. Miller indices are given. (b) Image showing the pore structure in K-AP. The variation of contrast along the line in the image is given in (i) where pore spacing (arrows) and wall thickness (dashed lines) are indicated. (c) Image of the pore structure in K-900 with DDP inset obtained from the area indicated by the dashed box. The Miller index of the visible spots is given. (d) Image showing the pore structure of $\mathrm{K}-900$. The variation of contrast along the line in the image is given in (ii) where pore spacing (arrows) and wall thickness (dashed lines) are indicated. (e) Image of K-900 showing the nonporous, amorphous silica prevalent within the sample.

The TEM images of KIT-6 in Figure 7 reveal very similar behavior to that of SBA-15 in that there was shrinkage of the unit cell and of the pores on thermal treatment and those regions with and without ordered pore structure were present in the thermally-treated sample, K-900. One difference seen in KIT- 6 over SBA-15 is that there appeared to be a thickening of the pore walls between K-AP and K-900, as indicated in Table 1.

In FDU-12 (Figure 8), the thermal treatment had a markedly different effect. The ordered structure of spherical pores seen in F-AP in Figure 7(a) was converted into material which still contained some of these pores but in which they were in a much less ordered arrangement, as seen in Figure 8(c) for F-900. In this sample, no pores were detected by gas adsorption (Figures 3 and 4) yet the SAXS patterns did indicate some ordered structure, although the peaks were much attenuated compared to those for F-AP. These results can be explained by reference to the TEM images. In these, pores were still seen in F-900 and formed a loosely ordered arrangement. However, it appears that the pores had become completely encapsulated within the silica material meaning that gas could not adsorb inside them in the gas adsorption experiments. This indicates that the narrow cylindrical channels forming connections between the spherical pores in the F-AP material must have failed, filling with silica material and leaving behind encapsulated spherical pores in arrangements ordered enough to be detectable by SAXS but which did not contribute to the measured surface area or pore volume of the sample because they were no longer accessible. This is in agreement with the findings of Kruk and Hui for the encapsulation of the spherical pores in large pore FDU-12 and SBA-16 on heating [31]. 


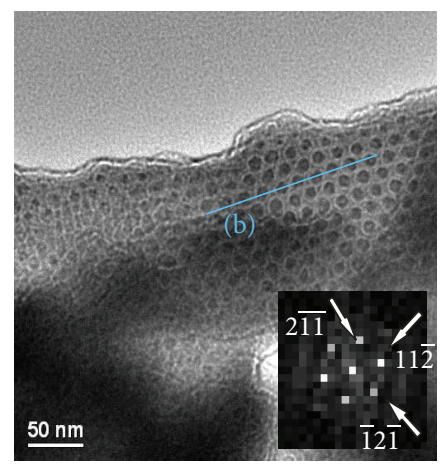

(a)

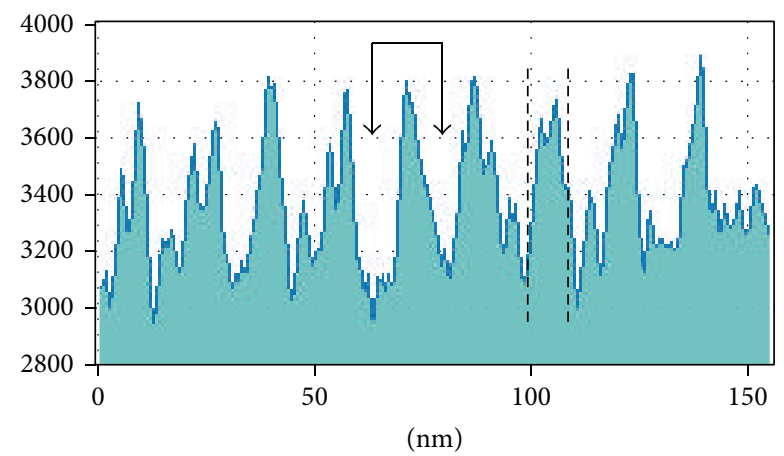

(b)

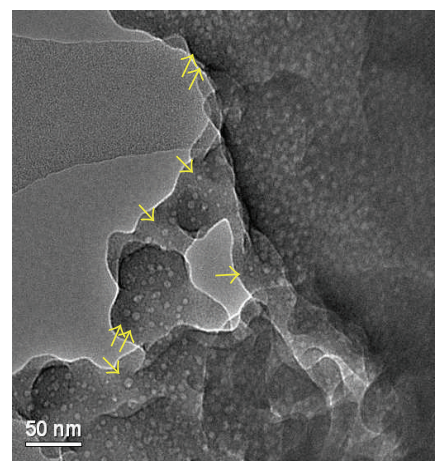

(c)

FIGURE 8: TEM images for FDU-12. (a) Image of F-AP with DDP inset. Miller indices are given (b). The variation of contrast along the line in the image shown in (a). Pore spacing (arrows) and wall thickness (dashed lines) are indicated. (c) Image of F-900 showing the amorphous silica surrounding a residual pore structure containing entombed pores (examples indicated with arrows).

3.4. Solid State ${ }^{29} \mathrm{Si}$ NMR. ${ }^{29} \mathrm{Si}-\mathrm{MAS}-\mathrm{NMR}$ spectra were recorded for each of the three OMS materials after four treatments: AP, 400, 650, and 900. The spectra are presented in Figure 9. All spectra showed a major peak at a chemical shift, $\boldsymbol{\delta}$, of around $-110 \mathrm{ppm}$ with small shoulders at higher $\boldsymbol{\delta}$. The spectra were deconvoluted into up to three Gaussian peaks [35]. These were assigned as Q2, Q3, and Q4 in order of decreasing $\boldsymbol{\delta}$, according to the convention for identifying the distinct $\mathrm{Si}$ environments in silicas and related materials [36]. All peak positions are summarised in Table 2. The Q2 resonance at $\boldsymbol{\delta} \sim-92 \mathrm{ppm}$ corresponds to $\mathrm{Si}$ atoms

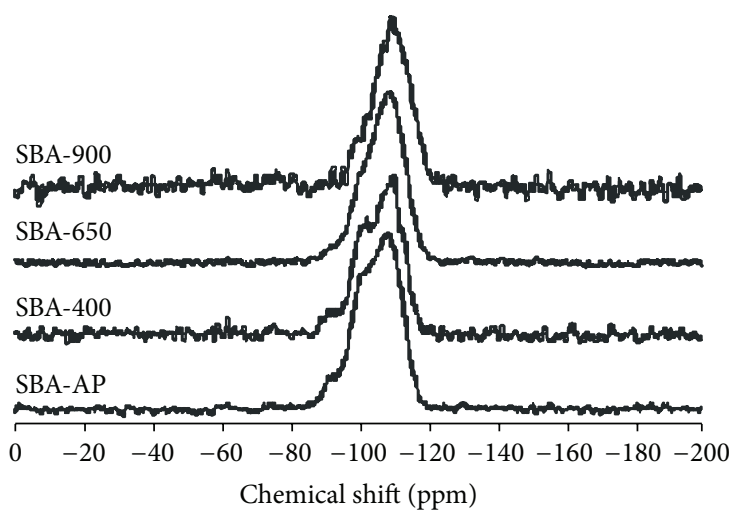

(a)

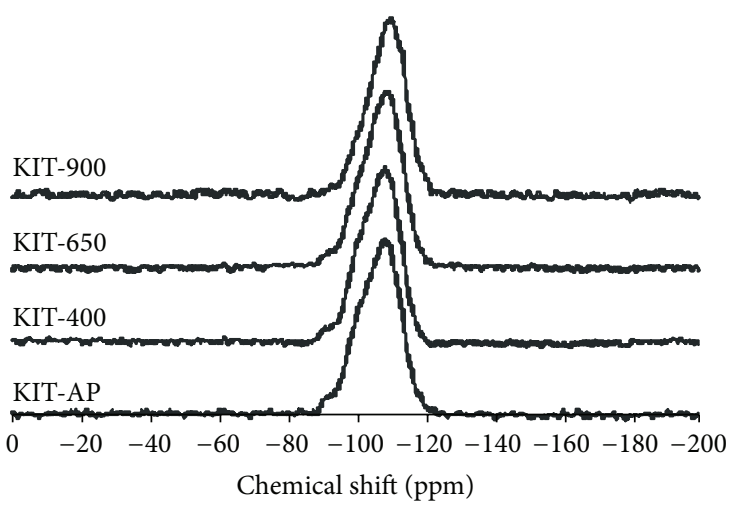

(b)

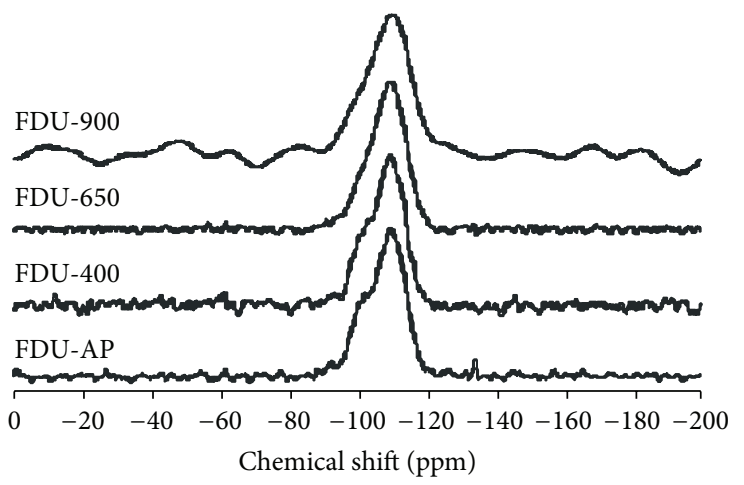

(c)

FIgURE 9: The resonance intensity of ${ }^{29} \mathrm{Si}$-MAS-NMR as a function of chemical shift for (a) SBA-15, (b) KIT-6, and (c) FDU-12 before deconvolution. The values have been offset from the baseline vertically for the purposes of clarity.

bonded to two siloxane groups and two silanol groups, the Q3 resonance at $\boldsymbol{\delta} \sim-101 \mathrm{ppm}$ is attributed to $\mathrm{Si}$ atoms with three siloxane bonds and one silanol group, and Q4 at $\boldsymbol{\delta} \sim 110 \mathrm{ppm}$ is ascribed to $\mathrm{Si}$ atoms with four siloxane bonds. This is shown schematically in Figure 10. The main peak in all spectra corresponded to the Q4 environment. The relative intensities of the Q2-Q4 resonances as a function of treatment temperature for the three OMS materials are plotted in Figure 11. For all three OMS structures, the general trend is for progressive decreases in Q2 and Q3 and 
TABLE 2: Chemical shifts, $\boldsymbol{\delta}$ (ppm), from the ${ }^{29}$ Si MAS-NMR spectra of SBA-15, KIT-6, and FDU-12 recorded after the pretreatments indicated. The positions of the main peak in the raw spectra (data) and of the three peaks obtained by deconvolution (Q2-Q4) are given.

\begin{tabular}{lccccccccccc}
\hline & \multicolumn{4}{c}{ SBA-15 } & \multicolumn{4}{c}{ KIT-6 } & \multicolumn{3}{c}{ FDU-12 } \\
& AP & 400 & 650 & 900 & AP & 400 & 650 & 900 & AP & 400 & 650 \\
\hline Data & -108.8 & -110.1 & -108.7 & -109.8 & -108.7 & -108.6 & -109.4 & -110.1 & -109.8 & -109.8 & -109.7 \\
Q2 & -91.7 & -91.8 & -94.3 & - & -91.8 & -91.4 & -91.4 & -90.9 & -92.1 & -92.8 & -93.2 \\
Q3 & -100.6 & -100.7 & -100.3 & -99.4 & -100.2 & -100.6 & -100.3 & -101.4 & -100.9 & -101.1 & -100.9 \\
Q4 & -108.9 & -109.3 & -108.8 & -110.0 & -108.9 & -109.1 & -109.2 & -110.2 & -110.1 & -109.9 & -109.8 \\
\hline
\end{tabular}<smiles>C[Si](C)(C)O[Si](O)(O)O[Si](C)(C)C</smiles><smiles>C[Si](C)(C)O[Si](O)(O[Si](C)(C)C)O[Si](C)(C)C</smiles><smiles>C[Si](C)(C)O[Si](O[Si](C)(C)C)(O[Si](C)(C)C)O[Si](C)(C)C</smiles>

FIGURE 10: Pictorial representation of the silanol and siloxane bonding configurations of a central $\mathrm{Si}$ atom which are representative of the Q2, Q3, and Q4 NMR resonance spectra.

a corresponding increase in Q4, starting from around $400^{\circ} \mathrm{C}$. It is therefore evident that thermal treatment caused progressive condensation of the $\mathrm{Si}-\mathrm{OH}$ groups. Since these are expected to be present predominantly at the surfaces of the materials where the silica structure is terminated, this behavior is consistent with the loss of pore structure seen using other techniques above. The biggest change was recorded for SBA-15, suggesting that this is less thermally stable than the KIT-6. The traces for SBA-15 and KIT-6 showed a change towards increasing percentage of Q4 which continued up to the pretreatment temperature of $900^{\circ} \mathrm{C}$ whereas the trace for the FDU-12 appeared to reach a plateau at the higher temperatures.

\section{Discussion}

Values of the key dimensions relating to the pore structures of the three OMS materials both as-prepared and after thermal treatment at $900^{\circ} \mathrm{C}$ are collected together in Table 1. Data obtained from the gas adsorption, SAXS, and TEM measurements are compared and show good general agreement. This is despite the difficulties in measuring pore diameter

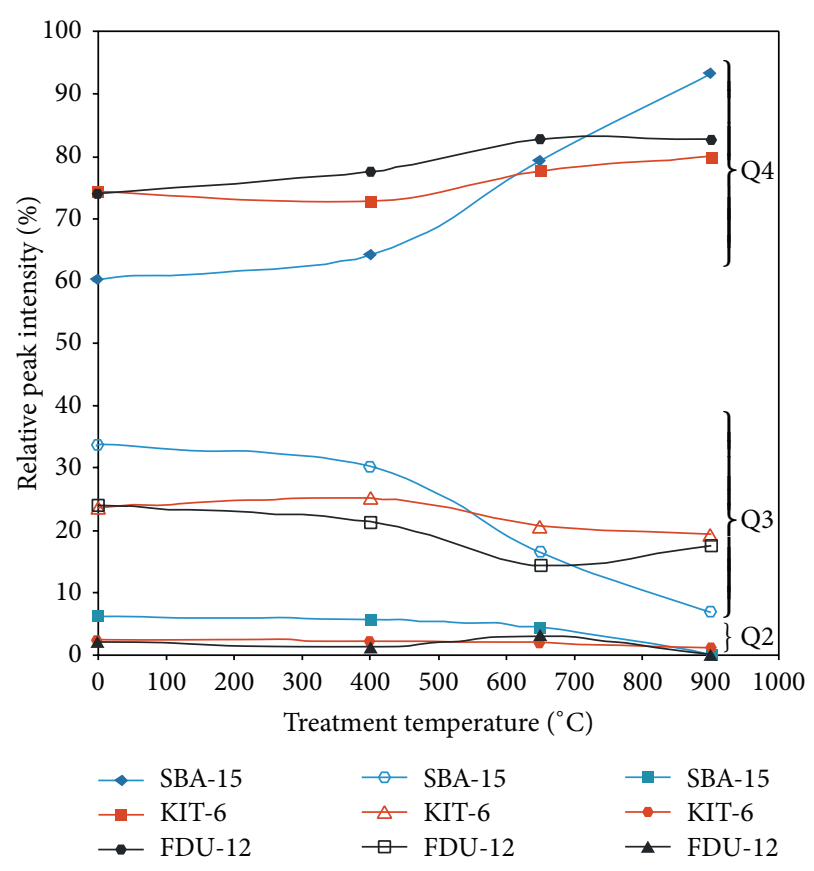

FIGURE 11: The peak intensity percentage of Q2, Q3, and Q4 resonances as a function of each treatment temperature for SBA-15, KIT-6, and FDU-12.

by TEM and locating the smallest peaks precisely in SAXS patterns, especially those relating to samples treated at high temperature. These data-when taken with the trends in the d-spacings shown in Figure 4-indicate a contraction of the unit cells in all three materials. This was more significant in SBA-15 and KIT-6 than in FDU-12. The gas adsorption results in Figures 2 and 3 and the pore widths measured by TEM together attest to a gradual decrease in pore size and a considerable loss of SSA with increasing treatment temperature for the SBA-15 and KIT-6 materials. Nevertheless, these two materials retained significant SSA and $V_{\text {meso }}$ values even after treatment at $900^{\circ} \mathrm{C}$. This was not the case for FDU-12 which appeared to suffer a complete loss of SSA and $V_{\text {meso }}$ in Figure 2(c) while pore size (Figure 3) did not change with treatment temperature. However, the trends in d-spacings for this material (Figure 4) show a smaller contraction than for the other two materials and the TEM images of F900 (Figure 7) show that this sample retained many pores. This apparent contradiction can be explained if these pores 
had become isolated from the external gas atmosphere and therefore inaccessible in the gas adsorption experiments. This is confirmed by study of the TEM images of F-900 in which the narrow channels connecting the larger spherical pores seem to have been filled and by the coincident complete loss of both $V_{\text {meso }}$ and $V_{\text {micro }}$ (Figure 2(c)). Despite being isolated, these pores still retained some structural order which was detected by SAXS. It appears that a different process occurred in SBA-15 and KIT-6-which do not contain large, spherical pores-and whereby their cylindrical pores were gradually filled. After treatment at $900^{\circ} \mathrm{C}$, loss of pore volume was broadly similar for these two materials, although SBA-15 lost more SSA than KIT-6. The NMR results also clearly indicate more significant condensation of $\mathrm{Si}-\mathrm{OH}$ groups-associated with loss of surface area-for the SBA-15. On balance, this suggests that the SBA-15 is the less thermally stable structure of the two and this is consistent with its one-dimensional pore structure which might be expected to be more vulnerable to contraction than the cubic, bicontinuous intertwined channel structure of KIT-6. Another, subtle, difference is that the pore walls in SBA-15 appeared to remain the same thickness as treatment temperature increased whereas those of KIT6 showed evidence of an increase in thickness in TEM (Table 1). However, there is no necessity for the walls in SBA-15 to become thicker when the pore diameters and the dimensions obtained from SAXS decrease. Because of the two-dimensional pore structure of SBA-15, contraction parallel to the pores is not detected in SAXS. The data indicate, therefore, that contraction may not in fact occur along the pores but only parallel to them. Further work would be needed to confirm this.

\section{Conclusions}

By performing a systematic study on three widely-used and representative OMS materials-SBA-15, KIT-6, and FDU12 - using complementary analysis techniques, the effect on their pore structures of thermal treatment was examined in detail.

Broadly speaking, SBA-15 and KIT-6 maintain their original pore structures to treatment temperatures of $600^{\circ} \mathrm{C}$ while FDU-12 maintains its pore structure to $500^{\circ} \mathrm{C}$.

SBA-15 and KIT- 6 exhibited similarities in the contraction of their pore structures and reduction in SSA. They differed, however, in the mode of structural collapse indicating that stability was likely influenced by the nature of the pore structure, that is, 2-D as opposed to 3-D. FDU-12 exhibited a somewhat different behavior in which the narrow channels between its larger spherical pores filled first, isolating the pores from the external gas atmosphere.

${ }^{29}$ Si MAS NMR data clearly showed a shift to higher Q values (Q2 and Q3 to Q4) in all three structures, implying the progressive loss of $\mathrm{Si}-\mathrm{OH}$ groups through condensation with increasing treatment temperature.

Since these and related materials are increasingly widely considered and applied for processes involving exposure to high temperatures-such as catalysis, gas storage, and nanocasting-it is hoped that these findings will help facilitate informed choices of structure type and of preparation and operating conditions for such applications.

\section{Conflict of Interests}

The authors declare that there is no conflict of interests regarding the publication of this paper.

\section{Acknowledgments}

The authors thank the School of Chemistry, University of St Andrews for Ph.D. funding for John B. Lowe and the EPSRC National Solid-state NMR Service at Durham, UK, and Dr. D. C. Apperley and colleagues and the solid state NMR service at St Andrews for ${ }^{29} \mathrm{Si}$ MAS-NMR.

\section{References}

[1] C. T. Kresge, M. E. Leonowicz, W. J. Roth, J. C. Vartuli, and J. S. Beck, "Ordered mesoporous molecular sieves synthesized by a liquid-crystal template mechanism," Nature, vol. 359, no. 6397, pp. 710-712, 1992.

[2] D. Zhao, J. Feng, Q. Huo et al., "Triblock copolymer syntheses of mesoporous silica with periodic 50 to 300 angstrom pores," Science, vol. 279, no. 5350, pp. 548-552, 1998.

[3] Q. Huo, D. I. Margolese, and G. D. Stucky, "Surfactant control of phases in the synthesis of mesoporous silica-based materials," Chemistry of Materials, vol. 8, no. 5, pp. 1147-1160, 1996.

[4] J. S. Beck, J. C. Vartuli, W. J. Roth et al., "A new family of mesoporous molecular sieves prepared with liquid crystal templates," Journal of the American Chemical Society, vol. 114, no. 27, pp. 10834-10843, 1992.

[5] F. Kleitz, S. H. Choi, and R. Ryoo, "Cubic Ia3d large mesoporous silica: synthesis and replication to platinum nanowires, carbon nanorods and carbon nanotubes," Chemical Communications, vol. 7, no. 17, pp. 2136-2137, 2003.

[6] X. Y. Liu, B. Z. Tian, C. Z. Yu et al., "Room-temperature synthesis in acidic media of large-pore three-dimensional bicontinuous mesoporous silica with Ia3d symmetry," Angewandte Chemie-International Edition, vol. 41, pp. 3876-3878, 2002.

[7] D. Zhao, Q. Huo, J. Feng, B. F. Chmelka, and G. D. Stucky, "Nonionic triblock and star diblock copolymer and oligomeric sufactant syntheses of highly ordered, hydrothermally stable, mesoporous silica structures," Journal of the American Chemical Society, vol. 120, no. 24, pp. 6024-6036, 1998.

[8] J. Fan, C. Z. Yu, F. Gao et al., "Cubic mesoporous silica with large controllable entrance sizes and advanced adsorption properties," Angewandte Chemie, vol. 42, no. 27, pp. 3146-3150, 2003.

[9] M. W. Anderson, "Simplified description of MCM-48," Zeolites, vol. 19, no. 4, pp. 220-227, 1997.

[10] H. Tuysuz and F. Schuth, "Chapter two-ordered mesoporous materials as catalysts," Advances in Catalysis, vol. 55, pp. 127$239,2012$.

[11] Y. Ren, Z. Ma, and P. G. Bruce, "Ordered mesoporous metal oxides: Synthesis and applications," Chemical Society Reviews, vol. 41, no. 14, pp. 4909-4927, 2012.

[12] K. P. D. Jong, Synthesis of Solid Catalysts, Wiley-VCH, Weinheim, Germany, 2009. 
[13] Y. Ren, B. Yue, M. Gu, and H. He, "Progress of the application of mesoporous silica-supported heteropolyacids in heterogeneous catalysis and preparation of nanostructured metal oxides," Materials, vol. 3, no. 2, pp. 764-785, 2010.

[14] H. Y. Huang, R. T. Yang, D. Chinn, and C. L. Munson, "Aminegrafted MCM-48 and silica xerogel as superior sorbents for acidic gas removal from natural gas," Industrial and Engineering Chemistry Research, vol. 42, no. 12, pp. 2427-2433, 2003.

[15] S. Zheng, F. Fang, G. Zhou et al., "Hydrogen storage properties of space-confined NaAlH4 nanoparticles in ordered mesoporous silica," Chemistry of Materials, vol. 20, no. 12, pp. 39543958, 2008.

[16] T. Asefa and Z. Tao, "Mesoporous silica and organosilica materials-review of their synthesis and organic functionalization," Canadian Journal of Chemistry, vol. 90, no. 12, pp. 10151031, 2012.

[17] S.-W. Song, K. Hidajat, and S. Kawi, "Functionalized SBA-15 materials as carriers for controlled drug delivery: influence of surface properties on matrix-drug interactions," Langmuir, vol. 21, no. 21, pp. 9568-9575, 2005.

[18] Z. A. Alothman, "A review: fundamental aspects of silicate mesoporous materials," Materials, vol. 5, no. 12, pp. 2874-2902, 2012.

[19] O. Y. Gutiérrez, G. A. Fuentes, C. Salcedo, and T. Klimova, "SBA-15 supports modified by $\mathrm{Ti}$ and $\mathrm{Zr}$ grafting for NiMo hydrodesulfurization catalysts," Catalysis Today, vol. 116, no. 4, pp. 485-497, 2006.

[20] H. Yang and D. Zhao, "Synthesis of replica mesostructures by the nanocasting strategy," Journal of Materials Chemistry, vol. 15, no. 12, pp. 1217-1231, 2005.

[21] A.-H. Lu and F. Schüth, "Nanocasting: a versatile strategy for creating nanostructured porous materials," Advanced Materials, vol. 18, no. 14, pp. 1793-1805, 2006.

[22] J. S. Lee, S. H. Joo, and R. Ryoo, "Synthesis of mesoporous silicas of controlled pore wall thickness and their replication to ordered nanoporous carbons with various pore diameters," Journal of the American Chemical Society, vol. 124, no. 7, pp. 1156-1157, 2002.

[23] B. Liu and R. T. Baker, "Factors affecting the preparation of ordered mesoporous $\mathrm{ZrO}_{2}$ using the replica method," Journal of Materials Chemistry, vol. 18, no. 43, pp. 5200-5207, 2008.

[24] A. Kong, H. Zhu, W. Wang, Q. Zhang, F. Yang, and Y. Shan, "Novel nanocasting method for synthesis of ordered mesoporous metal oxides," Journal of Porous Materials, vol. 18, no. 1, pp. 107-112, 2011.

[25] F. Gao, Q. Lu, X. Liu, Y. Yan, and D. Zhao, "Controlled synthesis of semiconductor $\mathrm{PbS}$ nanocrystals and nanowires inside mesoporous silica SBA-15 phase," Nano Letters, vol. 1, no. 12, pp. 743-748, 2001.

[26] S. A. Johnson, P. J. Ollivier, and T. E. Mallouk, "Ordered mesoporous polymers of tunable pore size from colloidal silica templates," Science, vol. 283, no. 5404, pp. 963-965, 1999.

[27] C.-T. Yang and M. H. Huang, "Formation of arrays of gallium nitride nanorods within mesoporous silica SBA-15," Journal of Physical Chemistry B, vol. 109, no. 38, pp. 17842-17847, 2005.

[28] F. Kleitz, W. Schmidt, and F. Schüth, "Calcination behavior of different surfactant-templated mesostructured silica materials," Microporous and Mesoporous Materials, vol. 65, no. 1, pp. 1-29, 2003.

[29] R. Ryoo, C. H. Ko, M. Kruk, V. Antochshuk, and M. Jaroniec, "Block-copolymer-templated ordered mesoporous silica: array of uniform mesopores or mesopore-micropore network?" Journal of Physical Chemistry B, vol. 104, no. 48, pp. 11465-11471, 2000.

[30] P. Shah and V. Ramaswamy, "Thermal stability of Mesoporous SBA-15 and Sn-SBA-15 Molecular Sieves: an in situ HTXRD study," Microporous and Mesoporous Materials, vol. 114, no. 13, pp. 270-280, 2008.

[31] L. Huang, X. Yan, and M. Kruk, "Synthesis of ultralarge-pore FDU-12 silica with face-centered cubic structure," Langmuir, vol. 26, no. 18, pp. 14871-14878, 2010.

[32] M. Kruk and C. M. Hui, "Thermally induced transition between open and closed spherical pores in ordered mesoporous silicas," Journal of the American Chemical Society, vol. 130, no. 5, pp. 1528-1529, 2008.

[33] M. Mandal and M. Kruk, "Surfactant-templated synthesis of ordered silicas with closed cylindrical mesopores," Chemistry of Materials, vol. 24, no. 1, pp. 149-154, 2012.

[34] H. Tüysüz, C. W. Lehmann, H. Bongard, B. Tesche, R. Schmidt, and F. Schüth, "Direct imaging of surface topology and pore system of ordered mesoporous silica (MCM-41, SBA-15, and KIT-6) and nanocast metal oxides by high resolution scanning electron microscopy," Journal of the American Chemical Society, vol. 130, no. 34, pp. 11510-11517, 2008.

[35] M. Luhmer, J. B. D’Espinose, H. Hommel, and A. P. Legrand, "High-resolution 29Si solid-state NMR study of silicon functionality distribution on the surface of silicas," Magnetic Resonance Imaging, vol. 14, no. 7-8, pp. 911-913, 1996.

[36] X. S. Zhao, G. Q. Lu, A. K. Whittaker, G. J. Millar, and H. Y. Zhu, "Comprehensive study of surface chemistry of MCM-41 using 29Si CP/MAS NMR, FTIR, pyridine-TPD, and TGA," Journal of Physical Chemistry B, vol. 101, no. 33, pp. 6525-6531, 1997. 

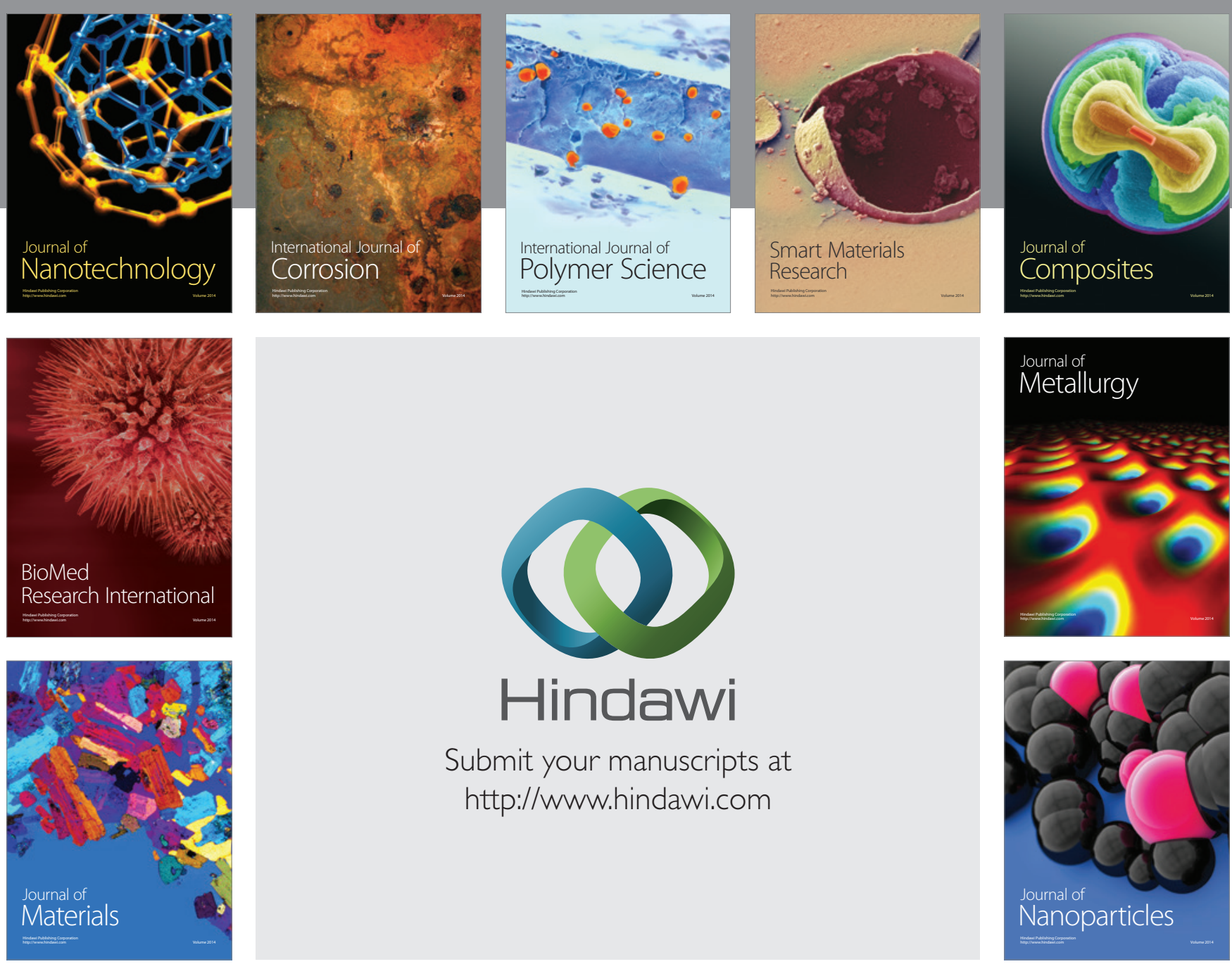

Submit your manuscripts at http://www.hindawi.com
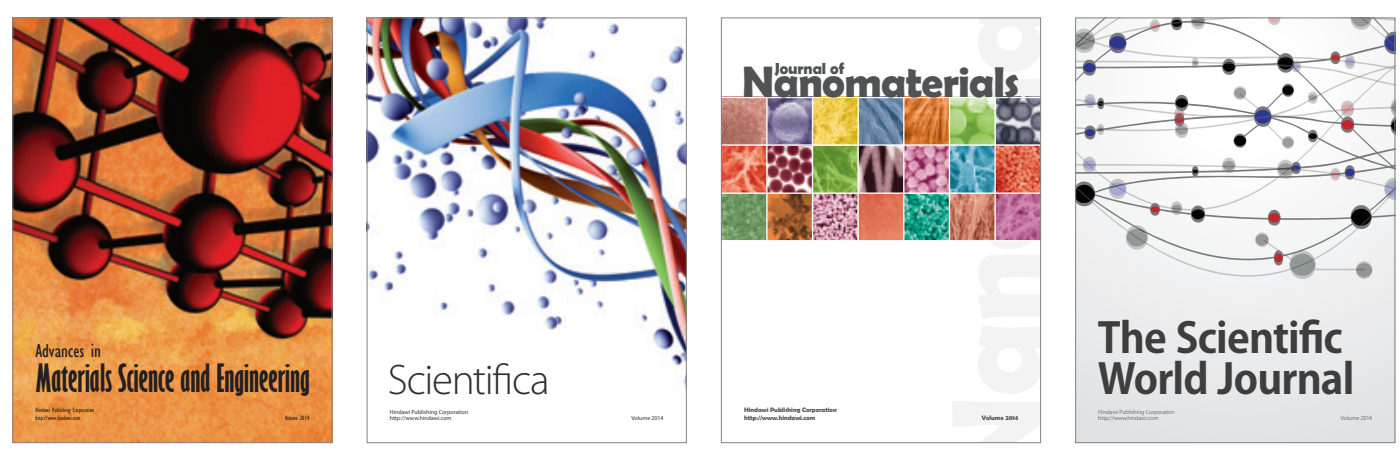

\section{The Scientific World Journal}
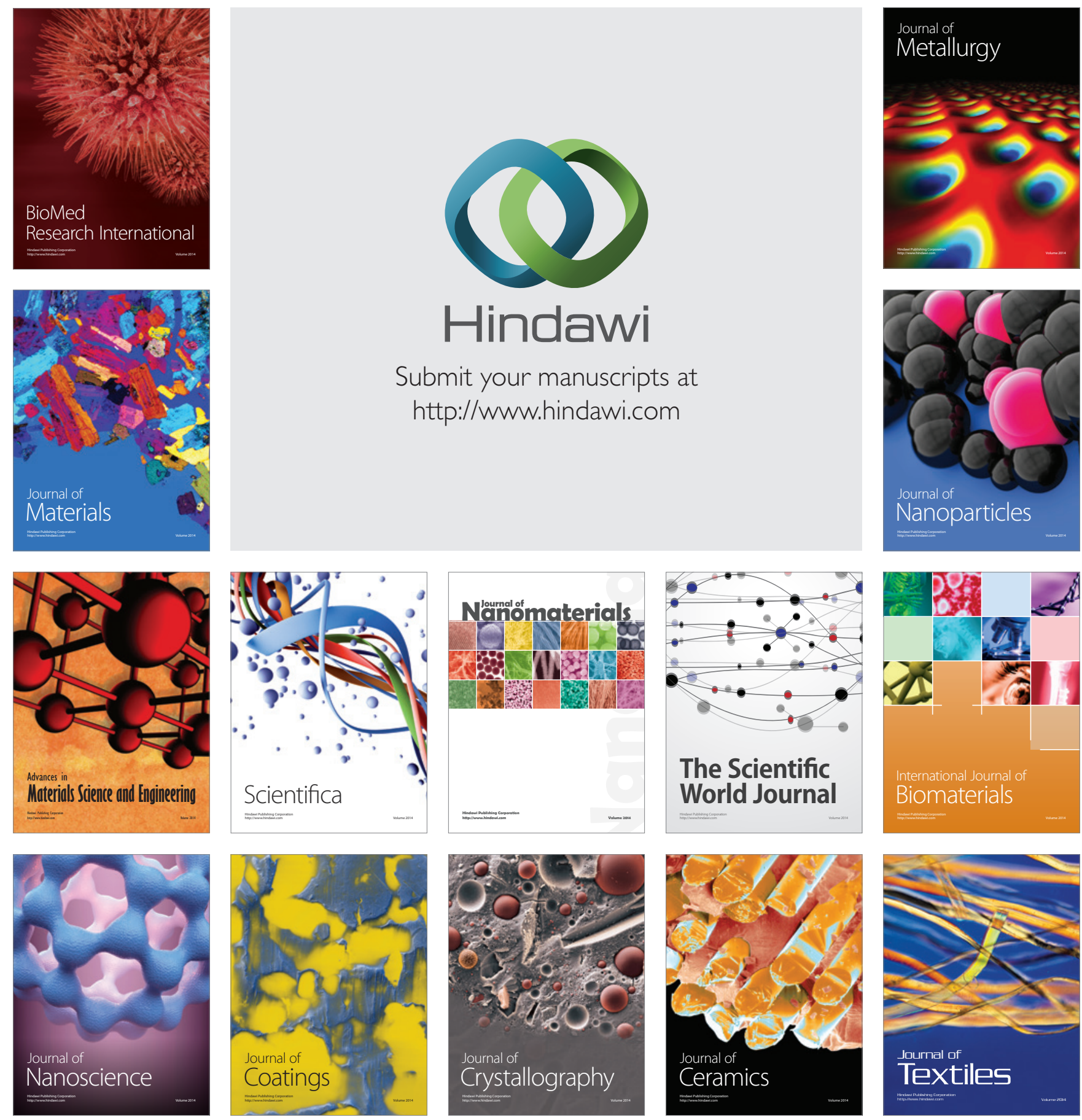